American Journal of Agricultural and Biological Sciences 5 (2): 122-127, 2010

ISSN 1557-4989

(C) 2010 Science Publications

\title{
Factors Influencing the Design of Electronic learning system in Agricultural Extension
}

\author{
${ }^{1}$ Amir Ahmadpour, ${ }^{1}$ Mehdi Mirdamadi, ${ }^{1}$ Jamal F. Hosseini and ${ }^{2}$ Mohamad Chizari \\ ${ }^{1}$ Science and Research Branch, Department of Agricultural Extension and Education, \\ Islamic Azad University, Tehran, Iran \\ ${ }^{2}$ Department of Agricultural Extension and Education, \\ Tarbiat Modarres University, Tehran, Iran
}

\begin{abstract}
Problem statement: Nowadays appropriate training and education are important. Still some organizations make the mistake of not training their employees adequately in the utilization of ICT or in the use of internet information systems, often due to the cost of providing training and the loss in productivity when employees are absent. But many organizations have adopted e-learning as a solution for their corporate training. The Ministry of Agriculture (MoA) also have considered the necessity of e-learning in agricultural extension for training extension agents as human resources that are working in extension centers throughout the country and have direct interaction with farmers, because they understand that traditional education is no longer effective. As a result, understanding factors influencing e-learning system in Iran's agricultural extension centers is crucial for creating the new opportunities for extension agent to update their information. The purpose of this study was to determine the factors affecting to design an e-learning system. Approach: The research in terms of nature is a kind of quantitative research and in terms of goal is applied research, in terms of controlling the variables is descriptive and correlation kind, which has been carried out in a survey way. Statistical population of the study consisted of 6539 extension expert in extension centers in Iran. Based on the classification of the Ministry of Agriculture which has divided these centers into six regions, sample taking has been conducted using stratified proportionate random sampling technique. Sample size for the students is 400 people using Cochran formula. Considering the entire size of the sample, 379 questionnaires have been returned. Results: With using factor analysis the variables were classified into seven factors, which they are included: financial, policy, support, personal, educational, technical and organizational factors. The confirmatory factor analysis determined that the relationship between observed variables and latent variables in the model. Conclusion: Extension agents will continue to play a crucial role in agricultural extension, therefore to accomplish this role in the best manner there is a need of applying new and effective methods to train extension experts in this field. On the other hand, for access to this goal, finding factors influencing the design of electronic education in agricultural extension is necessary. In this research we found some of factors that should be considered before implementation of any e-learning programs in any extension systems.
\end{abstract}

Key words: E-learning, training and education, agricultural extension

\section{INTRODUCTION}

In these challenging and rapidly changing times, organizations are becoming more convinced that the only lasting differentiator and source of competitive advantage is their human capital. According to Hall (2000), executives increasingly realize that the fate of their companies rests on their employees' ability to absorb information rapidly and learn the skills necessary to adapt to a constantly changing environment. This has led to a rush in finding and adopting a new way of delivering training known as "online learning" or "elearning". Electronic learning (e-learning) refers to communication and learning activities through computers and networks (Tsai and Machado, 2002).

Many organizations; institutes; universities; schools and corporations are investing substantial amounts of time and money in developing online alternatives to traditional types of education and training systems. Elearning in agriculture related fields is still in the early

Corresponding Author: Amir Ahmadpour, Science and Research Branch,

Department of Agricultural Extension and Education, Islamic Azad University, Tehran, Iran 
phases of adoption. The Ministry of Agriculture in Iran like many other organization and educational centers has considered the necessity of e-learning in agricultural extension network for training extension agents.

Every year extension agents are trained in different on-the-job training courses regularly. Holding such training courses in training centers requires a considerable time and money, because extension agents from different offices should leave the office for training centers. With providing online training we can save time and money and train a bigger group simultaneously. Therefore e-learning as a modern approach in training can be used to improve the effectiveness and efficiency of training in extension services (Hemmati and Sefidian, 2006).

Lippert and Plank (1999) also emphasize on Appling e-learning in this cases. They noted that it is an effective, very flexible delivery method and it brings the added benefit of being able to have experts and specialists from different regions and states in the same class without transportation and lodging costs, many types of learners are receptive to using the Internet and e-learning (Lippert and Plank, 1999). Several studies, including one by Lippert and Plank (1999) ultimately proved, with strong support of all of the participating learners, that "the Internet can be an effective way to implement an in-service training within the US Cooperative Extension Service" (Lippert and Plank, 1999). There is little doubt as to e-learning's efficacy for training extension agents, the challenge for the future will be to design and market e-learning directly for the farmers.
MOA usually uses the traditional face-to-face methods to train extension agents, but this methods often fails for several reasons including (1) the number of extension agents is considerably high (6536 persons); (2) the extension agents are scattered throughout the country (in 1213 extension center in 32 provinces); (3) this method of traditional learning is very costly, difficult to manage and implement. It seems that e-learning would be an appropriate solution for solving this problem. In the other hand, according to Karmakar and Wahid (2009) developing and expanding e-learning brings many opportunities for organizations including (1) saving time, money and effort; (2) addressing training needs from remote areas; (3) providing self-learning opportunities; (4) having a positive impact on the learning process; (5) providing a mechanism for collaborative learning (Karmakar, 2000). Also through the e-learning systems, workers have access to various on-line databases, tools and the most advanced skills that help them find solutions for work-related problems (Zhang and Nunamaker, 2003).

The purpose of this study was to determine the factors affecting to design an e-learning system.

Literature review: This literature review will cover some existing literature reviews on factors influencing an electronic learning system. Some variables in the research selected from previous studies and some others from interviews with some experts in the field of elearning in agricultural sector. Many studies have identified important variables dealing with an electronic learning system.

In Table 1, some of these studies are summarized.

Table 1: Related references about the factors influencing an e-learning system

\begin{tabular}{|c|c|}
\hline Author & Factors \\
\hline Chapnick (2000) & Psychological, sociological, environmental, human resource, financial, technological skill (aptitude), equipment and content \\
\hline Rosenberg (2001) & Infrastructure concern, technology concern, connectivity and learning management system \\
\hline Broadbent (2001) & Human resources, Infrastructure, knowledge and capital \\
\hline MacDonald et al. (2001) & $\begin{array}{l}\text { Superior structure( learner needs, learning environment, pedagogical, learner evaluation, learner motivation, program goal, } \\
\text { strategies, learner convenience), superior content (comprehensive, authentic, industry driven research), superior delivery } \\
\text { (usability, interactivity, tools, instructional strategies), superior service( resources, administrative and technical support, staff } \\
\text { accessibility, responsiveness), superior outcomes( lower cost for learner and employer, personal advantages for learner, } \\
\text { superior learner outcomes), continual adaptation and improvement, ongoing program evaluation }\end{array}$ \\
\hline Kurtus (2002) & Learner, needs of learner, the role of instructor \\
\hline Surry (2002) & Resources, infrastructure, human, strategies, learning, evaluation, support \\
\hline Schonwald (2003) & Organization, Technology, Culture, Strategy and Management \\
\hline Broadbent (2003) & Technology change, business case, Culture, Resources, Leadership, Talent, Speed for change \\
\hline Rusten and Ramirez (2003) & Connectivity and access, capacity building, content, application development, conducive governance and policy \\
\hline Neville (2004) & Learner, instructor, technical support and management \\
\hline $\begin{array}{l}\text { Borotis and Poulymenakou } \\
\text { (2004) }\end{array}$ & Environment, content, technology, culture, human resources and economic \\
\hline Jonsson (2005) & Technology, content, instructors and learner \\
\hline Barajas and Owen (2000) & Infrastructure, hard ware, soft ware, skills, cultural and organizational. \\
\hline Sribhadung (2006) & $\begin{array}{l}\text { Use of the internet and acceptable use policies, connectivity infrastructure and network, intergovernmental issues, } \\
\text { cost, finance, partnership intellectual property and copy right, }\end{array}$ \\
\hline Khan (2008) & Evaluation, interface design, technological, pedagogical, institutional, ethical, resource support, management \\
\hline Omidi et al. (2008) & Financial, technical experts, instructors, technical, organizational strategies and learner \\
\hline Jen-Her et al. (2008) & Institute, Learner and instructor \\
\hline
\end{tabular}


Am. J. Agri. \& Biol. Sci., 5 (2): 122-127, 2010

Table 2: Target and sample population

\begin{tabular}{lcc}
\hline Province & $\begin{array}{l}\text { Total number of } \\
\text { extension experts }\end{array}$ & Sample \\
\hline Gilan & 116 & 47 \\
West azarbayjan & 183 & 74 \\
Khorasan razavi & 192 & 67 \\
Lorestan & 193 & 72 \\
Isfahan & 89 & 36 \\
Fars & 228 & 83 \\
Total & 1021 & 379 \\
\hline
\end{tabular}

\section{MATERIALS AND METHODS}

This is a quantitative research with applied goal. As far as controlling variables is a descriptive and correlation research. Face validity of the research instrument was done by committee members and some experts in this field. For examining reliability of the research instrument, 30 questionnaires were filled by extension experts in Mazandaran province. For each part of the questionnaire Alpha Cronbach coefficient was separately calculated. Based on the results of this test and the acquired coefficient, some questions were eliminated and some others were modified. In overall the reliability of questionnaire was more than 0.89 . Statistical population of the study consisted of 2745 extension expert in the sector of agriculture in Iran. Based on the classification of the Ministry of Agriculture which has divided these centers into six regions, sample taking has been conducted using stratified proportionate random sampling technique. Sample size for the extension expert is 400 persons using Cochran formula. From 400 questionnaires, 379 questionnaires have been returned (Table 2).

This research used two statistical packages, SPSS 16 and Lisrel 8.5 to analyze the data. The data were analyzed using the some techniques include: exploratory factor analysis and confirmatory factor analysis. We use confirmatory factor analysis to confirm the model obtained from exploratory factor analysis. It means that the Goodness of the model must be measured by fitting an equation model (SEM) to the data and then using statistics that are available in the SEM like Root Mean Square Error of Approximation (RMSEA), RMSEA less than 0.05 indicates good fit, 0.05-0.08 indicates reasonable fit and higher than 0.08 represents average (Kalantari, 2009).

\section{RESULTS}

The results of descriptive statistics show that the average age of extension agents were 39.66 years old with 15.39 years work experience. Majority of them were male (93\%). It was also reported that more than 93\% of respondents studied in the filed of agriculture. Table 3 shows the details.
Table 3: Descriptive statistics of extension experts

\begin{tabular}{lll}
\hline Sex & Female (7\%) & Male (93\%) \\
Age/year & Mean=39.66 & SD =7.65 \\
Work experience/year & Mean = 15.39 & SD $=8.14$ \\
Management experience/year & Yes (35\%) & No (65\%) \\
Education background & Agriculture (93.5\%) & Others (6.5\%) \\
Degree & B.Sc.: 67.8 & $\begin{array}{l}\text { M.Sc. and } \\
\text { higher: } 9\end{array}$ \\
\hline
\end{tabular}

Table 4: Extension experts' skill related to e-learning

\begin{tabular}{lll}
\hline & Yes (\%) & No (\%) \\
\hline Acquiring ICDL skills certificate & 56.5 & 43.5 \\
Using internet (for obtaining information) & 78.1 & 29.1 \\
\hline
\end{tabular}

As we see in Table 4, 56.5\% of extension agents, have ICDL skills certificate and $78.1 \%$ of them uses internet for searching information.

Using factor analysis we classified factors into seven factors (latent variables). The variables were classified into financial, policy, support, personal, educational, technical and organizational (Table 5). The basic idea of factor analysis is to find a set of latent variables that contain the same information.

\section{DISCUSSION}

As the factor analysis showed, the factors were categorized into seven groups that ordered by the magnitude of their impact in Table 5 and Fig. 1.

Financial factors consider the budget and allocation process. Based on the results, financial factors are superior to the other factors. In effect, this factor has the strongest predictive power with $34.87 \%$ of variance in the model. The findings about financial factors are in accordance with those of Khan (2008); Omidi et al. (2008); Broadbent (2001); Surry (2002); Chapnick (2000) and Sribhadung (2006). The financial factor, plays an important and critical role (Broadbent, 2003) because the base and setting of e-learning system such as telecommunication infrastructure, buying computer, access to internet, Expense of maintenance of equipment and other ICT resources needs financial and credit and continuing e-learning projects needs investment (Borotis and Poulymenakou, 2004). It shows that MoA should be allocate the necessary budgets and secure the cost of training would have affect on the e-learning.

In the process of designing every e-learning project, it is necessary for policy makers and managers to understand the necessity of proper policies. The policy factor is including strategies for application and development of e-learning systems. Policy factor determine $9.86 \%$ of variance in the model. The importance of policies pointed out by Rusten and Ramirez (2003) and Karimi (2007). 
Table 5: Classification of factors by using factor analysis

\begin{tabular}{|c|c|c|}
\hline Factor & Variables & Variance by factor \\
\hline \multirow[t]{10}{*}{ Financial } & Financial sources for buying hardware equipment & 34.87 \\
\hline & Financial sources for buying software equipment & \\
\hline & Financial sources for maintenance of equipment & \\
\hline & Financial sources for upgrading and changing pieces & \\
\hline & Financial sources for basic training on ICT & \\
\hline & Financial sources for primary training on e-learning & \\
\hline & Financial sources for supporting and up-to-date training & \\
\hline & Financial sources for preparing content of educational course & \\
\hline & Financial sources for preparing digital content & \\
\hline & Budget for recruitment of experts & \\
\hline \multirow[t]{7}{*}{ Policy } & Comprehensive plan for developing learning technologies & 9.86 \\
\hline & Government investment in developing infrastructures for ICT & \\
\hline & Government policies of e-learning at macro-level the priority of e-learning in Gov. & \\
\hline & ICT policies programs for encouraging investment in e-learning & \\
\hline & Improving computer knowledge and skills for all & \\
\hline & Appointing managers with positive attitude towards ICT & \\
\hline & Enacting appropriate Acts for e-learning in organizations & \\
\hline \multirow[t]{5}{*}{ Support } & Supporting learner & 7.42 \\
\hline & Supporting instructor & \\
\hline & Incentives for learner for using e-learning. & \\
\hline & Incentives for instructor for using e-learning & \\
\hline & Continuous support to solve problems & \\
\hline \multirow{8}{*}{ Personal } & Beliefs about electronic learning & 7.08 \\
\hline & Positive attitude towards the use of modern technology & \\
\hline & Positive attitude towards life long learning & \\
\hline & Appreciation of the diversity of needs and interests skills of ICT & \\
\hline & Intention for collaboration and participation in learning process & \\
\hline & Intention to self-directed and independent learning accepting the facilitatory role of trainer & \\
\hline & Motivation for learning through electronic devices & \\
\hline & Believing the effectiveness of ICT in learning and training & \\
\hline \multirow[t]{7}{*}{ Educational } & Continuous evaluation of learners achievements & 6.05 \\
\hline & Standard courses development and presentation feedback to learners & \\
\hline & Educational achievement & \\
\hline & Shift in approach from teacher-centered to learner-centered approach shift from controlled & \\
\hline & Education to deliberate education free & \\
\hline & Providing the opportunity for learners to analyze learning content & \\
\hline & New method for iteration and collaboration new methods for organizing the content & \\
\hline \multirow[t]{5}{*}{ Technical } & Access to appropriate hard ware equipment & 4.51 \\
\hline & Access to appropriate soft ware equipment & \\
\hline & Providing appropriate telecommunication infrastructure & \\
\hline & Access to internet network & \\
\hline & Establishment of ICT educational centers & \\
\hline \multirow[t]{5}{*}{ Organizational } & Role of management on setting e-learning in institute establishing quantitative & 2.4 \\
\hline & and qualitative standards for e-learning in organization & \\
\hline & Consideration Attention to ICT application & \\
\hline & Readiness of organization to accept e-learning & \\
\hline & Providing human resources & \\
\hline Total & & 72.19 \\
\hline
\end{tabular}

RMSEA $=0.065$. The value of Root Mean Square Error of Approximation (RMSEA) show reasonable fit of model

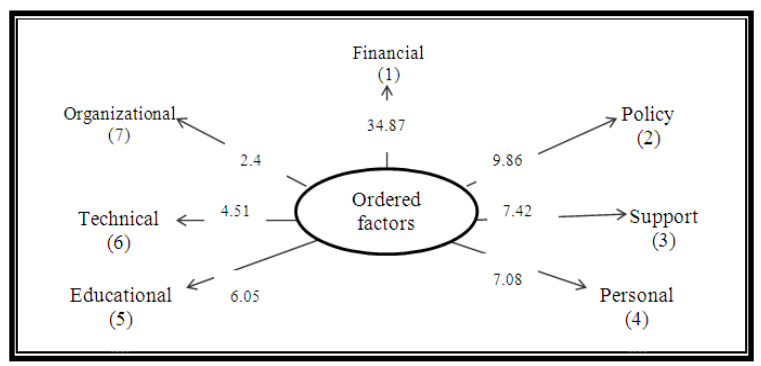

Fig. 1: Factors influencing the design of electronic education system in agricultural extension
E-learning programs for successful and sustainable implementation should be supported. This support, should involve learners and instructors. Our findings corroborate those of Surry (2002); Khan (2008) and MacDonald et al. (2001).

Chapnick (2000) expresses that psychological dimension considers the individual's state of mind as it impacts the outcome of the e-learning initiatives (Chapnick, 2000) as a part of Personal factors. This factor also involving observable and measurable technical competencies. The importance of Personal factors pointed out by several authors, such as 
MacDonald et al. (2001). If people did not have positive attitude, knowledge and skills of ICT, the elearning program fails. Knowledge and skills have a direct impact on using e-learning. Therefore, we suggest that the MoA improve ICT knowledge and skills of extension agents. There are evidences that show MoA follows the policy of developing knowledge and skill of extension agent about ICT.

Another factor is educational. For identifying the mechanisms of operating e-learning programs, appropriate learning approach should be concerned. The findings about educational factors are in accordance with those of Khan (2008) and Sun et al. (2008).

Technical factors considers the question of the proper equipment possession The importance of technical factors pointed out by several authors, such as Barajas and Owen (2000); Khan (2008); Omidi et al. (2008) and Surry (2002). MoA should pay more attention to provide appropriate hardware and software and infrastructure, because technical resources are one of sustainable implementation dimensions of e-learning (Schonwald, 2003).

The findings about organizational factors are in accordance with several authors, such as Schonwald (2003); Khan (2008); Surry (2002) and Barajas and Owen (2000). Organizations, not only must understand the potential of e-learning, but to create the appropriate organizational strategies and approaches to try and optimize the benefits they offer for ICT in education (Omidi et al. 2008).

\section{CONCLUSION}

It is obvious that many communities are trying to limit traditional training delivery methods and using elearning instead. Extension agents play a crucial role in agricultural extension, therefore to accomplish this role in the best manner, there is a need of applying new and effective methods to train extension experts in this field. On the other hand, for access to this goal, finding factors influencing the design of electronic education in agricultural extension is necessary. In this research we found some of factors that should be considered before implementation of any e-learning programs in agricultural extension system in Iran.

\section{REFERENCES}

Barajas, M. and M. Owen, 2000. Implementing virtual learning environments: Looking for a holistic approach. Educ. Technol. Soc., 3: 39-53. http://www.ifets.info/journals/3_3/barajas.html
Borotis, S.A. and A. Poulymenakou, 2004. e-learning readiness components: Key issues to consider before adopting e-learning interventions. Proceedings of the World Conference on ELearning in Corporate, (ELC'04), Government, Healthcare and Higher Education Washington DC., USA., pp: 1622-1629

Broadbent, B., 2001. Championing e-Learning. http://www.brookebroadbent.com/resources/Cham pioning+e-Learning.pdf

Broadbent, B., 2003.Getting a bigger slice of e-learning pie.

http://www.brookebroadbent.com/resources/Bigger + slice+of+pie.pdf

Chapnick, S. 2000. Are you ready for e-learning? Learning Circuits: ASTD's Online Magazine All About ELearning. http://www.astd.org/LC/2000/1100_chapnick.htm

Hall, B., 2000. Learning goes online: How companies can use networks to turn change into a competitive advantage. Cisco systems: Packet magazine.

Hemmati, A. and E. Sefidian, 2006. E-learning and investigation on its application in on-the job training for the staff of AREO, Proceeding of the Iranian Agricultural Education Seminar, Nov. 1-2, Tarbiat Modares University, Iran, pp: 221-232.

Jen-Her, W., R.D. Tennyson, T. Hsia and Y. Liao, 2008. Analysis of E-learning innovation and core capability using a hypercube model. Comput. Hum. Behav., 24: 1851-1866.

Jonsson, B.A., 2005. A case study of successful elearning: A web-based distance course in medical physics held for school teachers of the upper secondary level. Med. Eng. Phys., 27: 571-581.

Kalantari, K., 2009. Structional Equitation Modeling in Socio-Economic Research. 1st Edn., Farhange Saba Press, Tehran, Iran, ISBN: 987-964-2935-49-9, pp: 243.

Karimi, A.R., 2007. Assessment and qualitative analysis of capabilities of e-learning in Iran's higher education system. Master Degree Thesis, Department of Agricultural Extension and Education, College of Agriculture, Tarbiat Modares University, Iran, pp: 145.

Karmakar, C.K. and CM. Wahid, 2009. Recommendations for Bangladesh towards elearning readiness. Department of computer science. Shah Jalal University of Science and Technology.

http://www.codewitz.net/papers/MMT_97-

102_Karmakar_Wahid\%20.pdf 
Karmakar, C.K., 2000. Recommendations for Bangladesh towards e-learning readiness. Department of Computer Science. Shah Jalal University of Science and Technology.

Khan, B.H., 2008. Elements of e-learning quality. http://elexforum.etqm.ae/Archive/2008/downloads/ Presentations/Post\%20Forum\%20Workshops/Day $\% 201 /$ Elements $\% 20$ of $\% 20 \mathrm{e}-$

Learning\%20Quality\%20by\%20Badrul\%20Khan/ Elements\%20of\%20eLearning\%20Quality\%20by\%20Badrul\%20Khan.pdf

Kurtus, R., 2002. Initial considerations before designing e-learning, CBT or WBT. http://www.school-forchampions.com/elearning/initialconsid.htm

Lippert, R.M. and C.O. Plank, 1999. Response to a first time use of internet in service training by agricultural extension agents. J. Nat. Resour. Life Sci. Educ., 28: 53-56.

MacDonald, C.J., E. Stodel, L. Farres, K. Breithaupt and M.A. Gabriel, 2001. The demand driven learning model: A framework for web-based learning. Internet Higher Educ., 1: 9-30.

Neville, K., 2004. A Government crossing the digital divide to promote ICT for adult learners. Elect. J. e-Learn., 2: 145-158. http://www.ejel.org/volume2/vol2-issue1/issue1-art1-neville.pdf

Omidi, M.N., J.F. Hosseini, M. Mirdamadi and R. Moghadasi, 2008. Designing an Efficient Information and Communication Technology (ICT) system to train private agricultural insurance brokers in Iran. Aust. J. Basic Applied Sci., 2: 1041-1051.

Rosenberg, M.J., 2001. E-learning, Strategies for Delivering Knowledge in the Digital Age. McGraw-Hill Companies, New York, ISBN: 0-07136268-1, pp: 344.

Rusten, E. and S. Ramirez, 2003. Future direction in agriculture and Information and Communication Technologies (ICTs) at USAID. The Academy for Educational Development and Winrock International. http://www.winrock.org/agriculture/files/ag_ict.pdf
Schonwald, I., 2003. Sustainable implementation of elearning as a change process at universities. Proceeding of the 9th Online Educa, Dec. 3-5, Swiss Centre for Innovations in Learning, Berlin, pp: $1-5$. http://www.scil.ch/fileadmin/Container/Leistungen /Veroeffentlichungen/buecher/2003-12-onlineeduca-schoenwald.pdf

Sribhadung, R.A.P., 2006. Mobile device in e-learning. Proceeding of the 3rd International Conference on eLearning for Knowledge-Based Society, Aug. 3-4, Bangkok, Thailand pp: 35.1-5. http://www.ijcim.th.org/v14nSP1/pdf/p35.1-5-fin18.pdf

Sun, P., R. Tsai, G. Finger, Y. Chen and D. Yeh, 2008. What drives a successful e-Learning? An empirical investigation of the critical factors influencing learner satisfaction. Comput. Educ., 50: 1183-1202.

Surry, D.W., 2002. A model for integrating instructional technology into higher education. Proceeding of the Conference on American Educational Research Association, Apr. 2002, New Orleans DW., pp: 1-1.

Tsai, S. and P. Machado, 2002. E-learning, online learning, web-based learning, or distance learning: Unveiling the ambiguity in current terminology. http://www.elearnmag.org/subpage.cfm?section=be st_practices\&article $=6-1$

Zhang, D. and J.F. Nunamaker, 2003. Powering elearning in the new millennium: An overview of elearning and enabling technology. Inform. Syst. Front., 5: 207-218. DOI: 10.1023/A:1022609809036 